\title{
The potential market demand for biokinetics in the private health care sector of South Africa
}

\author{
Sarah J Moss (PhD) ${ }^{1}$ \\ Martie S Lubbe (PhD) ${ }^{2}$ \\ ${ }^{1}$ Niche Area for Physical Activity Sport and Recreation (PhASRec) in the School of Biokinetics, Recreation and Sport Science, North-West \\ University (Potchefstroom Campus), Potchefstroom \\ ${ }^{2}$ Niche Area for Medicine Use in South Africa (MUSA) in the School of Pharmacy, North-West University, Potchefstroom
}

\begin{abstract}
Objective: Biokinetics, a profession registered with the Health Professions Council of South Africa (HPCSA), address inter alia chronic diseases of lifestyle (CDL) with exercise as treatment modality. The purpose of this investigation is to determine the potential market demand for biokinetic services in the private health care sector of South Africa.

Methods: Data from a pharmaceutical benefit management system (PBM) were analysed to determine the prevalence of chronic diseases in the private health care sector for 2007. Telephonic interviews on a sub-sample of 50 biokineticists revealed the average number of patients that can be treated monthly per biokineticist. The number of biokineticists with active practice numbers was obtained from the Board of Health Care Funders (BHF).

Results: The results indicate that $47 \%$ (747 199/1 600 000) of the patients managed by the PBM are treated with medication for one or more CDL. Non-steroid anti-inflammatory medication $(21 \%)$, medication for cardiovascular diseases $(13 \%)$ and bronchodilators (11\%) had the highest prevalence. The sub-sample of biokineticists indicated that one biokineticist can treat an average of 100 patients per month. The potential market demand calculated from the above numbers indicated that 7472 biokineticists are needed in the private health care sector, while only 625 active practice numbers were registered with the BHF in 2007.

Conclusion: In conclusion, it is estimated that only $7.6 \%$ of patients with $\mathrm{CDL}$ can potentially be treated by the current number of registered biokineticists. Therefore an enormous market potential for biokinetics exists in the private health care sector of South Africa.
\end{abstract}

\section{CORRESPONDENCE:}

Professor S J Moss

PhASRec in the School of Biokinetics, Recreation and Sport Science

North-West University (Potchefstroom Campus)

Potchefstroom, 2520

Tel: 0182991821

Fax: 0182856028

E-mail: Hanlie.moss@nwu.ac.za

\section{Introduction}

Chronic diseases of lifestyle (CDL) are on the increase in South Africa as in the rest of the world. This increase in the number of communicable and non-communicable diseases has labelled South Africa as a country with a 'double burden of disease. ${ }^{1} \mathrm{CDL}$ are a group of diseases that share similar risk factors as a result of exposure, over many decades, to unhealthy diets, smoking and lack of exercise and possibly stress. ${ }^{2}$ These risk factors further include inter alia high blood pressure, high blood cholesterol, diabetes and obesity. These risk factors present in various disease processes such as stroke, heart attacks, certain cancers, chronic bronchitis and many others that culminate in high mortality and morbidity rates. ${ }^{3}$

Research has indicated that regular physical activity can positively address all above-mentioned pathological conditions and thereby reduce the mortality and morbidity rates in populations. ${ }^{3}$ Biokinetics has drawn on and implemented this body of evidence to prescribe scientifically based exercise programmes to prevent and manage non-communicable diseases in South Africa. In developed countries physical inactivity is estimated to cause $6.0 \%$ of all deaths for men and $6.7 \%$ for women. ${ }^{4}$ A study investigating the cost-effectiveness of health care-based interventions aimed at improving physical activity found evidence for cost effectiveness in groups with high risk, such as older persons and persons with heart failure. ${ }^{5}$

In South Africa, biokinetics has been practised for the last 25 years after the scope of practice was published in the Government Gazette. ${ }^{6}$ Although the road to obtaining recognition was very difficult, $^{7}$ the profession has continued growing, with 12 training institutions training about 150 students every year. More than 1000 biokineticists have completed their training during the last 25 years, with the current register of the Board of Health Care Funders (BHF) reporting 799 active practice numbers for $2009 .^{8}$ The scope of practice for biokinetics deals with the prescription of scientifically based exercise for preventing and treating CDL as well as for finalphase rehabilitation of orthopaedic injuries. ${ }^{9}$

Biokineticists usually form part of a multidisciplinary team in the treatment of chronic diseases and orthopaedic injuries together with medical practitioners, physicians, physiotherapists and dieticians. In the South African health care sector, however, biokineticists only form part of the multidisciplinary team in the private health care sector. Research indicates that this formal private health sector is a large, well-developed, resource-intensive and highly specialised sector that provids health insurance coverage to some 7 million people. ${ }^{10}$ The other estimated 40 million South Africans make use of either the public health care system or traditional healers, or pay out of their pockets for private health care services. As biokineticists are not employed in the public health sector, except in the National 
Defence Force, people making use of the public health care system are not exposed to biokinetic intervention.

Although other health disciplines are attracted away from the public health sector with large financial and personal incentives, ${ }^{10}$ this is not the case with biokinetics. This lack of job opportunities in the public health sector has forced biokineticists to become entrepreneurs by starting private practices. These practices are solo practitioners, associations or partnerships with other biokineticists or other health practitioners. This is, however, not as straightforward as other entrepreneurial ventures. Strict ethical guidelines set by the HPCSA to guide the profession and protect the public against exploitation hamper biokineticists to do marketing to the same extent as unregistered/unregulated professions. ${ }^{9}$

In order to start any new venture, determining the market potential for the product is extremely important. As the purpose of all businesses is to create wealth, the product, price, packaging and place of sale should be thoroughly investigated. ${ }^{11}$ Health professionals are unfortunately seldom trained in business principles. This lack of business skills often results in the failure of biokinetic practices to be sustainable over a long period. This may create the perception that the potential market demand is too small to sustain the number of biokineticists trained annually. In the history of biokinetics in South Africa no studies have investigated the potential market demand for biokinetics, based on the services delivered by the profession to the public.

The purpose of this study was to determine the potential market demand for biokinetics in the private health care sector of South Africa. The results obtained from this investigation will shed some light on the potential number of biokineticists that could be trained per year, given no restrictions from the training institutions with regard to lecturing staff.

\section{Research methodology Data collection}

The study was an observational study to determine the potential market need for biokinetics. In order to understand the methodology, it is important to define the market. According to Wood ${ }^{12}$ the market potential is all the customers who may be interested in the service that is presented. It is, however, important to remember that some customers in this potential market are unaware of the product, some may not have access to it, some may not be able to use it and some may not be able to afford it. The potential market represents the maximum number of customers who might buy the product - but not the number who will realistically buy it. ${ }^{13}$

The approach that was followed (Fig. 1) was to determine the number of persons in the identified segment (persons with a chronic disease of lifestyle) that potentially require the service and the number of potential service delivery points (practising biokineticists) matching each other. This was performed within the South African private health care framework.

For the purpose of this study, the market segment that was identified to base the potential market demand on was that of persons with CDL and orthopaedic abnormalities. Although the scope of practice for biokineticists ${ }^{9}$ includes the pathogenic and the fortogenic (health promotion) paradigms, it was decided to focus only on the pathogenic paradigm for the purpose of this study. Because secondary data were used for the analyses, it was important to ensure that they are timely, unbiased, legitimate, reliable and qualified. ${ }^{12}$ In order to comply with these criteria, it was decided to make use of timely (2007), unbiased and reliable information from a private sector medicine claims database. The data are reliable as the database is

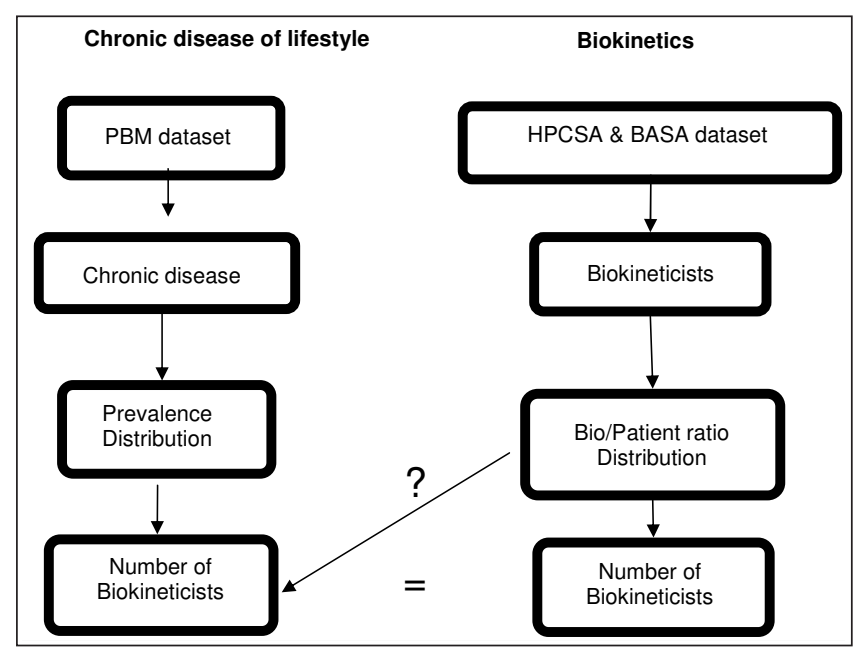

Fig. 1. A schematic presentation of the research methodological approach.

created online in real time as patients collect their prescriptions. The geographical area, according to postal code of the consultation room of the prescriber, was also captured.

The medicine claims data were from a pharmacy benefit management company (PBM). The PBM company administered medicine claims data of members of medical schemes from almost all community pharmacies and $98 \%$ of the dispensing doctors. For security, ethical, patient and provider identification reasons, PBM company was not identified by name.

\section{Prevalence of chronic diseases of lifestyle}

The Niche Area: Medicine Use in South Africa (MUSA) has the rights to use the medicine claims database of the specific PBM for research purposes. Ethical clearance was obtained from the Ethics Committee of the North-West University (Project number: NWU-0046-08-S5). This system is a fully integrated management system for more than 42 medical scheme clients administered by 17 different health care administrators. In 2007, 1.6 million South Africans benefited from this system. All medicines prescribed for chronic diseases were classified according to the coding system in the Monthly Index of Medical Specialties (MIMS) classification system, which classifies medicine according to its pharmacological action. ${ }^{14}$ A further classification of medicine information was performed with regard to the place (consultation room) of prescriber (province, district council, municipality and main place level).

The Statistical Analysis System ${ }^{\circledR}$, SAS $9.1^{\circledR 15}$ programme was used to group all prescribed practice addresses according to province, district council, municipality and main place level. This allowed the researchers to identify the number of diseases treated with medication and the number of patients who received chronic medicine in different geographical areas in South Africa.

From the database all chronic conditions where exercise is considered an appropriate treatment modality and that is addressed by biokineticists in their scope of practice as announced in the Government Gazette ${ }^{6}$ in 1983, were extracted to determine the national and provincial prevalence of the following chronic diseases in South Africa: hypertension, diabetes, obesity, dyslipidaemias, cardiovascular diseases, osteoporosis, depression and chronic obstructive pulmonary diseases (COPD).

\section{Biokineticist to patient/client ratio}

In order to determine the potential market for biokinetics in the private health care sector, the ratio of biokineticist to patient or client 


\begin{tabular}{|c|c|c|c|c|c|c|c|c|c|c|}
\hline $\mathrm{CDL}$ & $\begin{array}{l}\text { Eastern } \\
\text { Cape }\end{array}$ & Free State & Gauteng & $\begin{array}{l}\text { KwaZulu- } \\
\text { Natal }\end{array}$ & Limpopo & $\begin{array}{l}\text { Mpuma- } \\
\text { langa }\end{array}$ & $\begin{array}{l}\text { North- } \\
\text { West }\end{array}$ & $\begin{array}{l}\text { Northern } \\
\text { Cape }\end{array}$ & $\begin{array}{l}\text { Western } \\
\text { Cape }\end{array}$ & TOTAL \\
\hline $\begin{array}{l}\text { Anti- } \\
\text { depressants }\end{array}$ & 9080 & 8149 & 50763 & 16106 & 6854 & 5650 & 7692 & 2314 & 14993 & 122026 \\
\hline Epilepsy & 1547 & 1604 & 13583 & 5091 & 958 & 1081 & 1476 & 324 & 2717 & 28481 \\
\hline $\begin{array}{l}\text { Parkin- } \\
\text { sonism }\end{array}$ & 291 & 268 & 1807 & 593 & 145 & 154 & 235 & 60 & 557 & 4123 \\
\hline NSAID & 23214 & 16022 & 137497 & 48487 & 23156 & 19820 & 23304 & 5130 & 33836 & 332173 \\
\hline Gout & 1333 & 994 & 7708 & 2113 & 913 & 1150 & 999 & 233 & 2196 & 17681 \\
\hline $\begin{array}{l}\text { Osteopo- } \\
\text { rosis }\end{array}$ & 855 & 607 & 4815 & 1670 & 211 & 292 & 429 & 100 & 1851 & 10872 \\
\hline CVD & & & & & & & & & & 210248 \\
\hline $\begin{array}{l}\text { Inotropic } \\
\text { agents }\end{array}$ & 507 & 495 & 2384 & 1028 & 286 & 259 & 310 & 131 & 925 & 6345 \\
\hline $\begin{array}{l}\text { Arrhyth- } \\
\text { mias }\end{array}$ & 258 & 478 & 2155 & 610 & 83 & 157 & 210 & 66 & 735 & 4774 \\
\hline $\begin{array}{l}\text { Hyperten- } \\
\text { sion }\end{array}$ & 11570 & 9249 & 66102 & 22151 & 6365 & 6945 & 8467 & 2455 & 23559 & 157354 \\
\hline Angina & 4553 & 3012 & 19081 & 7236 & 2613 & 2415 & 2869 & 10704 & 7588 & 50587 \\
\hline Vasodilator & 50 & 104 & 782 & 97 & 54 & 69 & 142 & 32 & 107 & 1444 \\
\hline $\begin{array}{l}\text { Vasocon- } \\
\text { strictors }\end{array}$ & 233 & 270 & 2746 & 514 & 156 & 303 & 386 & 89 & 442 & 5138 \\
\hline $\begin{array}{l}\text { Hyperlipi- } \\
\text { daemia }\end{array}$ & 6393 & 4166 & 36455 & 10509 & 1986 & 2891 & 3519 & 875 & 14133 & 81204 \\
\hline $\begin{array}{l}\text { Bronchodi- } \\
\text { lators }\end{array}$ & 12471 & 7639 & & 27495 & 11095 & 10548 & 12764 & 2739 & 21642 & 175277 \\
\hline Asthma & 2478 & 2533 & 19964 & 6463 & 3479 & 1959 & 3083 & 508 & 4805 & 45367 \\
\hline Diabetes & 3388 & 2335 & 19638 & 7981 & 2557 & 2129 & 2586 & 693 & 6010 & 47459 \\
\hline Total & 76543 & 45905 & 403129 & 135009 & 54314 & 45662 & 46683 & 11029 & 92774 & 911212 \\
\hline
\end{tabular}

was also determined by means of a telephone survey. Biokinetics practice owners registered with the Biokinetics Association of South Africa (BASA) website were asked to indicate the average number of active clients/patients treated at their facility monthly, the number of biokineticists and intern-biokineticists working in the practice. The ratio of biokineticist to patient/client was determined from this information.

\section{Statistical analysis}

Descriptive statistics with frequency tables, mean \pm standard deviation and graphs were performed in order to determine the market potential for biokinetics in the private health sector. Mathematical calculations were performed to calculate the potential market need for biokineticists.

\section{Results}

The purpose of this study is to determine the potential market demand in the broad term for biokinetics in the private health care sector, specifically with reference to the pathogenic paradigm. In order to determine this potential demand the results will be presented by determining the prevalence of $\mathrm{CDL}$, reporting on the physical activity levels of the population and the available biokineticists and practices that address the CDL with exercise.

The prevalence of $\mathrm{CDL}$ as represented by chronic medication use from a medicine claims database of a PBM company indicated that 911212 chronic diseases were treated within the 1.6 million subscribers (Table I). The average age of the persons taking chronic medication for diseases related to CDL was $36.8 \pm 21.8$ years. The average age was calculated according to the age at the first prescription date. The females were slightly older than the males $(\mathrm{M}=35.4 \pm 21.9$ years; $\mathrm{F}=37.9 \pm 21.8$ years). Totals in the table do not add up, as a few claims could not be placed according to geographical region (provinces) but are included in the calculations.

The results of Table I indicate that the prevalence of CDL is $66 \%$ in the specific PBM database for 2007. It is however known that one person could be diagnosed and treated for more than one disease, as is often the case for persons with diabetes mellitus. The calculation of the number of patients represented by the prevalence of CDL in the PBM (Table II) indicates that $47 \%$ of persons registered with the PBM are treated for $\mathrm{CDL}$ and receiving medication for the $\mathrm{CDL}$. The prevalence of persons with CDL is the highest in the Gauteng province at $19 \%$, with the lowest prevalence the Northern Cape at $1 \%$.

When the results form Table II are further divided by age and ratio of female/male it shows that except for gout, the ratio of women obtaining chronic medication is higher than for men. The average age of the patients also indicate that lung disease is present mainly in the younger population, with the average age of persons treated with bronchodilators at $33.0 \pm 23.2$ years and those with asthma 
TABLE II. Prevalence of CDL according to the number of persons diagnosed and treated with medication for each of the provinces and in relation to the estimated population

\begin{tabular}{|c|c|c|c|}
\hline Provinces & Estimated population & Persons with CDL & $\%$ of the estimated population \\
\hline Eastern Cape & $6906200^{\S}$ & 46503 & 2.9 \\
\hline Free State & $2965600^{\S}$ & 33110 & 2.1 \\
\hline Gauteng & $9688100^{\S}$ & 300659 & 18.8 \\
\hline KwaZulu-Natal & $10014500^{\S}$ & 112948 & 7.1 \\
\hline Limpopo & $5402900^{\S}$ & 47221 & 2.9 \\
\hline Mpumalanga & $3536300^{\S}$ & 42221 & 2.6 \\
\hline North-West & $3394200^{\S}$ & 49895 & 3.1 \\
\hline Northern Cape & $1102200^{\S}$ & 11271 & 0.7 \\
\hline Western Cape & $4839800^{\S}$ & 100343 & 6.3 \\
\hline Not indicated & & 3028 & 0.2 \\
\hline Total & $47849800^{\S}$ & 747199 & 46.7 \\
\hline
\end{tabular}

medication $32.6 \pm 25.3$ years. The average age of people obtaining medication for cardiovascular diseases is $60-70$ years. Non-steroid anti-inflammatory medication (NSAID) is mostly prescribed to persons around the age of 45 years. This may be due to the onset of arthritis and joint and muscle pain from previous injuries.

The calculation from Fig. 2 indicates that from 1.6 million persons, 747199 persons are on medication for a CDL that could be treated through exercise intervention such as presented by biokineticists. This is further divided into 316894 persons suffering from a single disease and the rest treated for more than one disease within the $\mathrm{CDL}$. The prevalence of participants on anti-inflammatory medication is the highest $(21 \%)$, followed by patients who received medication for cardiovascular diseases $(13 \%)$ and then patients on bronchodilators $(11 \%)$ and medication for hypertension (10\%).

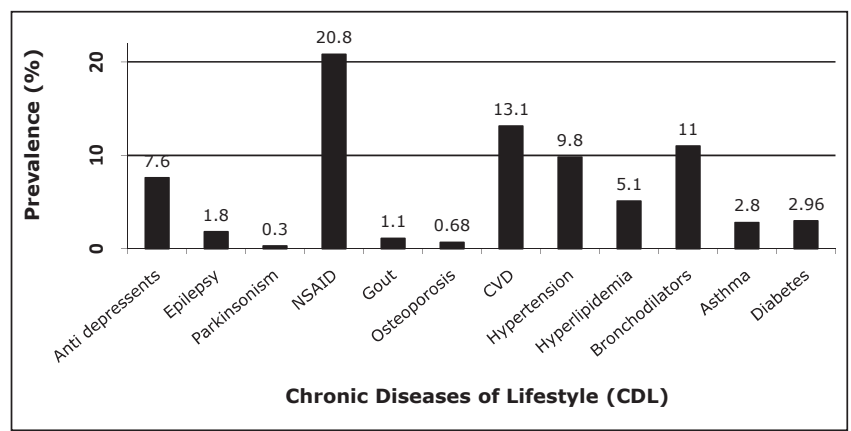

Fig 2. The prevalence (\%) of disease in participants on the PBM database taking medication for the different chronic diseases of lifestyle. (NSAID = non-steroid anti-inflammatory drugs; CVD = cardiovascular disease.)

\section{Physical inactivity profiles of South Africans}

As biokineticists address CDL with exercise as treatment, it is also important to report on the current levels of physical inactivity as it is a risk factor for CDL. ${ }^{3}$ Secondary data reported in the South African Health Review ${ }^{10}$ compared the levels of inactivity reported in the general population with those reported in a corporate survey (Table III). The results indicate that about $50 \%$ of the general population does not participate in levels of physical activity that would reduce or manage CDL.
TABLE III. A summary of the prevalence (\%) of physical inactivity reported in different surveys

\begin{tabular}{|c|c|c|c|}
\hline Surveys & Total (\%) & Males (\%) & $\begin{array}{l}\text { Females } \\
(\%)\end{array}$ \\
\hline 51 -country survey ${ }^{17}$ & 46.2 & 44.7 & 47.6 \\
\hline Youth risk behaviour $^{18}$ & 36.8 & 30.5 & 43 \\
\hline Corporate survey $^{19}$ & 69 & 62 & 75 \\
\hline SADHS $^{20}$ & 46 & 43 & 49 \\
\hline World Health Survey ${ }^{21}$ & 46 & 43 & 49 \\
\hline
\end{tabular}

\section{Current biokinetic practices}

In order to determine the market potential, the current number of biokineticists who render this service had to be determined. The number of practising biokineticists according to the BASA website, which is an optional place to register and not compulsory (Table IV), indicates 284 biokinetic practices. Seventy-one of the 284 practices are accredited to employ biokinetic interns (students in training who have to complete a final year of practical training before final registration with the HPCSA can be obtained). These practices may employ more than one biokineticist and a maximum of two interns per registered biokineticist. ${ }^{9}$

Data obtained from the $\mathrm{BHF}^{8}$ the management system for practice numbers that enables biokineticists and patients to claim from medical insurance, indicate 625 biokineticists with active practice numbers who were also registered with the HPCSA in 2007. The distribution of these practices within South Africa (Table IV) indicates that the majority of the practices are in the Gauteng province (130), with the second most in the Western Cape (63). This means that $46 \%$ of biokineticists are practising in and around Gauteng, while about $22 \%$ of the total pool of practising biokineticists is active in the Western Cape. This leaves about $32 \%$ of the biokineticists in the rest of South Africa.

\section{Ratio of biokineticist to patient/client}

A telephonic interview with 50 randomly selected available biokineticists indicated that each biokineticist could manage about 100 
(range 40 - 160) patients per month depending on the type of practice and the business strategy followed. There was an average of 2 biokineticists working in each practice. If every biokineticist managed 100 clients in South Africa from the specific PBM, where 747199 clients are treated for CDL, then 7438 biokineticists will be required in South Africa. Table IV indicates the current number of practising biokineticists with regard to each province together with the market potential based on the prevalence of chronic disease as indicated by the PBM system.

\section{TABLE IV. The relationship between the current number of practising biokineticists and the potential market need for the different provinces}

\begin{tabular}{|c|c|c|}
\hline Province & $\begin{array}{l}\text { Current number of } \\
\text { practices }(N)\end{array}$ & 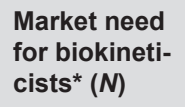 \\
\hline Eastern Cape & 19 & 465 \\
\hline Free State & 11 & 331 \\
\hline Gauteng & 130 & 3006 \\
\hline KwaZulu-Natal & 33 & 1129 \\
\hline Limpopo & 5 & 472 \\
\hline Mpumalanga & 9 & 422 \\
\hline North-West Province & 11 & 498 \\
\hline Northern Cape & 3 & 112 \\
\hline Western Cape & 63 & 1003 \\
\hline Total & 284 & $7438^{\S}$ \\
\hline \multicolumn{3}{|c|}{${ }^{*}$ Based on 100 patients/biokineticist. } \\
\hline \multicolumn{3}{|c|}{$\begin{array}{l}\S_{\text {Numbers differ due to some claims not being linked to original place of prescribin }} \\
\text { of medication. }\end{array}$} \\
\hline
\end{tabular}

\section{Discussion}

CDL are a reality in South Africa, a country with a double burden of disease that is created between CDL, also known as non-communicable diseases, and the infectious diseases such as HIVIAIDS and tuberculosis, also known as communicable diseases. The results of this study indicate that the prevalence of the CDL in this PBM system is $56 \%$ and represent $47 \%$ patients. The major three conditions represent nearly a third of all the total medicine expenditure managed by this studied PBM. This is much higher than the reported $37 \%$ of deaths attributed to CDL. ${ }^{18}$ Considering that most of the surveys report on data that were obtained either during $1998^{20}$ (SADHS) or until $2005,{ }^{2}$ it is therefore possible that the prevalence of CDL has increased substantially since the last survey.

Although the percentages are not very high, the corresponding numbers of persons who require treatment are substantial. If these percentages of prevalence for the various CDLs are extrapolated to the general population, estimated to be $47498000^{16}$ (StatsSA, 2009) at June 2007, it could mean that about 26795888 people in South Africa are diseased by one of the CDLs. Steyn et al. ${ }^{2}$ report that about 6 million people are living with hypertension, 4 million with diabetes and about 4 million have hyperlipidaemia. Steyn et al. ${ }^{2}$ also mention that about $56 \%$ of the population has at least one of these risk factors. The prevalence of CDL as found in this investigation based on the prescription of medication, observed comparable prevalence for hypertension and diabetes as reported by Puoane et al. ${ }^{23}$ Studies investigating the cost of managing CDL have highlighted the burden of CDL on an economy. ${ }^{23,24}$
When interpreting the data on CDL from a biokineticist's point of view, it is important to also consider the inactivity patterns in South Africa. The results indicate that females are more inactive than males, with people in the corporate sector reporting inactivity levels of close to $70 \%$ in the total for males and females. ${ }^{10}$ This is a daunting number of physically inactive persons who are often also exposed to high levels of stress in the work environment. These high levels of physical inactivity indicate that there is a huge potential for the management of chronic diseases with exercise and physical activity interventions, as the majority of the population are currently not participating in the required amount of activity as prescribed by the $\mathrm{ACSM}^{3}$ to achieve health outcomes.

The results of the number of biokineticists registered with the HPCSA that also have active practice numbers indicate that the approximately 625 biokineticists are most likely accommodated within the 284 biokinetics practices in South Africa. These are crude delineations as it is impossible to obtain the exact number of biokineticists who are actively earning a living as biokineticists. The reason is that persons on the register of the HPCSA continue to pay registration fees annually to ensure they stay on the role, even if they are not practising, in order to keep their registration. The reason for this behaviour is that it is difficult to obtain registration again once you have been deregistered and have not practised for a number of years. Another reason for inaccurate numbers on the BASA website is the fact that it is optional to register practices on the website. In spite of the inaccurate numbers, the data described are still the most accurate available that were used in the analysis and assumptions made.

The distribution of the biokinetics practices simulate the areas of high income in South Africa, with the most practices being in the Gauteng area and the least practices in the Northern Cape, which has the lowest income per capita. ${ }^{16}$ The population density in Gauteng is also higher than in the Northern Cape, resulting in shorter travelling distances between home and biokinetic practices. The analyses of the number of patients/clients that a biokineticist is able to treat per month indicated an average of 100 persons with a range of between 40 and 160 . There was an average of 2 biokineticists working per accredited practice.

In order to calculate the potential market demand for biokinetics, the potential number of persons taking medication for CDL according to the analysed PBM system was divided by 100 to determine the number of potential biokineticists needed. This calculation indicated that about 7438 biokineticists are needed. If an average of two persons work together, that means that about 3719 practices are potentially needed. The current number of biokinetic practices is therefore calculated to be rendering a service to only $8 \%$ of the potential market. As these are pure calculations to determine the market potential, it is necessary to take into account the factors that may hamper people from visiting a biokineticist for exercise as treatment of a CDL.

When calculating a market potential, the broadest market is first determined, ${ }^{12}$ as was done with this study. It is important to remember that these results are a crude indication of the potential market demand for biokinetics in the private health care sector. This study also only focused on the pathogenic paradigm, and not the fortogenic (health promotion) paradigm, where biokinetic intervention addresses the prevention of CDL. The section of the market that has the income to afford the service and has access to the product should be determined. Important factors that can influence the behaviour of the potential consumers will include gender, level of education, age, ethnic background and the perceived value for the client/patient, 
various social connections and personal elements, of which lifestyle would be the most prominent together with motivation.

A study investigating the factors that influence the demand for health care in South Africa using a multinomial logit estimation, found that there are three categories of factors that influence the demand. These factors are: (i) demographic and location variables (e.g. income, race and location); (ii) characteristics of the care provided (e.g. cost and distance from the respondent); and (iii) characteristics of the illness (such as severity). ${ }^{25}$ This study also found that an increase in income indicated a decrease in the use of primary health care. Where income was above R2 785 per month, primary health care was only utilised in less than $5 \%$ of the respondents. ${ }^{25}$ These results give an indication of the income group that can be expected to seek treatment for CDL as offered by biokinetics.

The limitations of this study were that the numbers on which the calculations are based are relative, although currently the most accurate available. The calculations from the PBM are also based on the prevalence of the 2007 data, as the classification of the 2008 data is not available. The number of biokineticists is also a crude number as accurate numbers are difficult to obtain. Registered biokineticists often become pharmaceutical representatives to earn a larger income while also learning business and marketing skills before returning to the profession.

\section{Conclusions}

The conclusion that can be drawn from this study is that there is a large potential market for biokinetics in the private health care sector of South Africa. Currently only an estimated $8 \%$ of the potential market is addressed by biokinetics with exercise as a treatment modality. This is only the calculation for the pathogenic paradigm. It therefore seems that the number of biokineticists trained annually could be increased to address the shortage in the market. However, an investigation is recommended to determine the factors that may prevent the large potential market demand from realising.

\section{REFERENCES}

1. Vorster HH, Kruger A. Chronic diseases of lifestyle in South Africa: the role of public health nutrition in the promotion of health, and prevention and treatment of disease. S Afr J Diab Vasc Dis 2006;3(4):179-181.
2. Steyn K, Fourie J, Temple N, eds. Chronic Diseases of Lifestyle in South Africa: 1995-2005. MRC - technical report. Cape Town: South African Medical Research Council, 2006:1- 266.

3. Thompson WR, ed. ACSM's Guidelines for Exercise Testing and Prescription, 8th ed. Philadelphia: Lippincott Williams \& Wilkins, 2009:152-206.

4. World Health Organization. World Health Report 2002. Geneva: WHO

5. Hagberg LA, Lindholm L. Cost-effectiveness of healthcare-based interventions aimed at improving physical activity. Scand J Public Health 2006;34:641-653.

6. The South African Medical and Dental Council - rules for the registration of medical scientists (Notice 673, 1983). Government Gazette, 1983;8879:19.

7. Strydom GL. Biokinetics: the development of a health profession from physical education - historic perspective. SAJR SPER 2005;27(2):113-128.

8. Board of Health Care Funders. www.bhfglobal.com. 2009 (accessed 10 September 2009).

9. Health Professions Council of South Africa (HPCSA). www.hpcsa.co.za 2009. (accessed 30 August 2009).

10. Harrison S, Bhana R, Ntuli A, eds. South African Health Review. Durban: Health Systems Trust, 2007.

11. Kotler P, Armstrong G. Principles of Marketing. 12th ed. Upper Saddle River, New Jersey: Pearson: Prentice Hall, 2008.

12. Wood MB. Marketing Planning: Principles into Practice. Harlow, England: Prentice Hall, 2004.

13. Roger JB. Market-Based Management: Strategies for Growing Customer Value and Profitability, 2nd ed. Upper Saddle River, NJ: Prentice Hall, 2000:59-62.

14. Snyman JR, ed. MIMS Monthly Index of Medical Specialities. MIMS: Pretoria. 2009.

15. SAS Institute Inc., 2003

16. Statistics South Africa. www.statssa.gov.za. 2008 (accessed 9 September 2009).

17. Guthold R, Ono T, Kathleen L, Strong KL, Chatterji S, Morabia A. Worldwide variability in physical inactivity: A 51-country survey. Am J Prev Med 2008;34(6):486-494.

18. Reddy SP, Panday S, Swart D, et al. Umthenthe Uhlaba Usamila - The South African youth at risk behaviour survey 2002. Cape Town: South African Medical Research Council.

19. Kolbe-Alexander TL, Buckmaster C, Nossel C. Chronic disease risk factors, healthy days and medicine claims in South Africa employees presenting for health risk screening. BMC Public Health 2008;8(228):1-11.

20. Department of Health, Medical Research Council. The South African Demographic Health Survey. Pretoria: Department of Health, 2002.

21. World Health Organization. Preliminary Results of the World Health Survey 2002-2003, International Physical Activity Data, South African results. Geneva: WHO, 2005.

22. Puoane T, Tsolekile L, Sanders D, Parker W. Chronic non-communicable diseases. In: Barron P, Roma-Reardon J, eds. South African Health Review. Durban: Health Systems Trust, 2008.

23. Kouris-Blazos A, Wahlqvist M. Health economics of weight management: evidence and cost. Asia Pac J Clin Nutr 2007;16(Suppl 1):329-338.

24. Ruchlin HS, Dasbach EJ. An economic overview of chronic obstructive pulmonary disease. Pharmacoeconomics 2001;19(6):623-642.

25. Havemann R, Van der Berg S. The demand for health care in South Africa. J Stud Econ Econometrics 2003;27(3):1-27. 